\title{
Wall Replication in Saccharomyces Species: Use of Fluorescein-conjugated Concanavalin A to Reveal the Site of Mannan Insertion
}

\author{
By J. S. TKACZ* AND J. O. LAMPEN $\dagger$ \\ Institute of Microbiology, Rutgers University, The State University \\ of New Jersey, New Brunswick, New Jersey, 08903, U.S.A.
}

(Accepted for publication 13 April 1972)

\begin{abstract}
SUMMARY
The wall mannan in dividing Saccharomyces cells was labelled by exposing the yeasts to fluorescein-conjugated concanavalin A. The yeasts were then allowed to grow in the absence of excess staining reagent and were examined by fluorescence microscopy at several intervals after the re-initiation of growth. The newly synthesized mannan was non-fluorescent and, thus, could be easily distinguished from the material present at the outset. Most new mannan was deposited in the wall surrounding the bud, and little if any of the mannan in the bud wall was derived from the surface of the mother cell. Deposition of new mannan in the mother cell was detected only in the bud scar. The distal tip of the growing bud was identified as the major site at which new mannan was inserted into the existing wall fabric. This area is also known to be the deposition site of newly synthesized glucan. Thus, with respect to these two major wall polysaccharides, wall replication in Saccharomyces cells resembles the apical mode exhibited by filamentous fungi.
\end{abstract}

\section{INTRODUCTION}

Concanavalin $\mathrm{A}$, the lectin from jack beans, may be conjugated with fluorescein and employed as a specific cytochemical staining reagent for the $\alpha$-mannan present in walls of certain yeasts such as Saccharomyces cerevisiae (Tkacz, Cybulska \& Lampen, I97I). In this communication we report the results of experiments in which fluorescein-labelled concanavalin A was used to determine the site at which newly synthesized mannan was deposited in the wall of a growing Saccharomyces cell. The experimental approach was, in essence, that used by Cole (1965) and others in the study of wall replication in bacteria.

\section{METHODS}

The strains of yeast employed were Saccharomyces cerevisiae LK2GI2 (obtained from C. Lindegren, Carbondale, Illinois, U.S.A.) and Saccharomyces hybrid strain 303-67 (supplied by P. Ottolenghi, Carlsberg Laboratories, Copenhagen, Denmark). Both strains are diploid, and the hybrid was derived from crosses involving $S$. carlsbergensis, $S$. chevalieri, and $S$. italicus (Winge \& Roberts, I957). Methods for the preparation of the fluoresceinconcanavalin A conjugate, for the maintenance of the yeast cultures, and for the staining, preparation and examination of specimens have been described previously (Tkacz et al. 1971).

* Present address: Laboratory for Carbohydrate Research, Massachusetts General Hospital, Boston, Massachusetts, 02114 , U.S.A.

$\dagger$ To whom reprint requests should be addressed. 

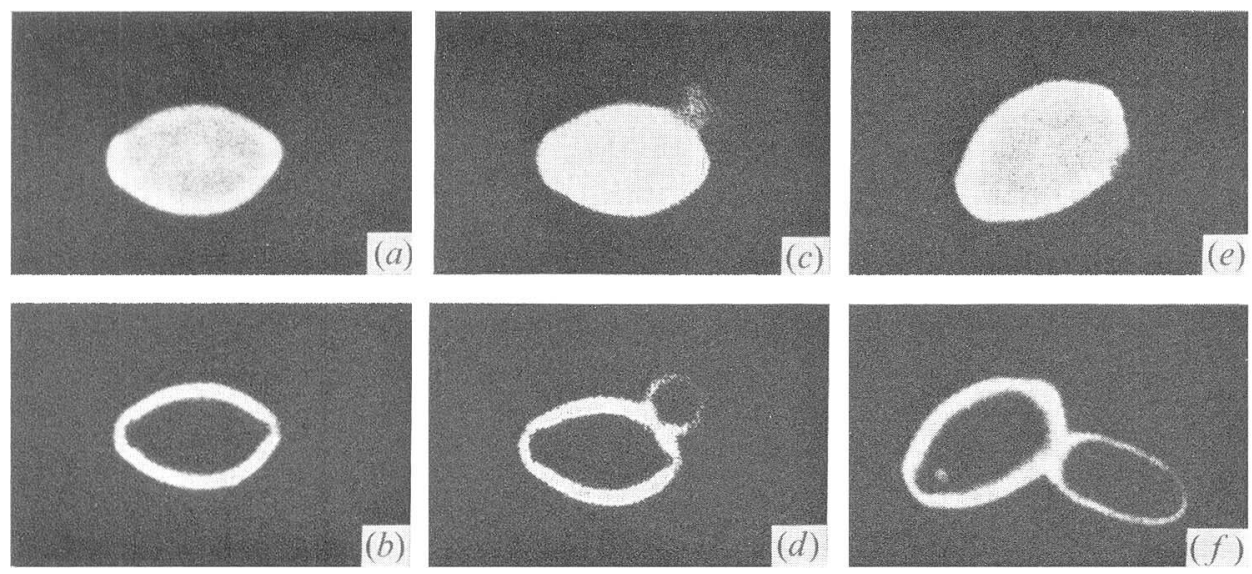

Fig. I. Reconstructed sequence showing the development of a yeast that was stained before bud formation with fluorescein-conjugated concanavalin A. Newly synthesized mannan is deposited about the growing bud. Photomicrographs were taken under both ultraviolet $(a, c, e)$ and dark-field $(b, d, f)$ illumination. In this and all other Figures, cells of Saccharomyces hybrid strain 303-67 are presented.

To obtain populations of randomly dividing yeasts, the yeasts were cultured overnight at $30{ }^{\circ} \mathrm{C}$ in a medium consisting of $0.3 \%(\mathrm{w} / \mathrm{v})$ yeast extract and $0.5 \%$ peptone (YEPmedium) supplemented with $\mathrm{I} \cdot 0 \%$ glucose. Following exposure to fluorescein-labelled concanavalin A, the cells were washed free of excess staining reagent and allowed to continue growth at room temperature (about $22{ }^{\circ} \mathrm{C}$ ) in YEP-medium containing $0 \cdot \mathrm{I} \%$ glucose. Mannan, which was synthesized and deposited in the wall after the application of labelled concanavalin A, was non-fluorescent and therefore could easily be distinguished from the wall mannan present at the outset. By observing the relative frequencies of the various staining patterns at several intervals (up to $3 \mathrm{~h}$ ) after the re-initiation of growth, a sequence of events could be inferred for yeasts which had been stained: (i) before bud formation; (ii) midway in the budding cycle; and (iii) late in the division cycle.

\section{RESULTS}

Identical results were obtained with both Saccharomyces strains examined, and it suffices, therefore, to present in detail the data obtained with only one of the strains (viz., Saccharomyces hybrid strain 303-67).

If the cell was exposed to the fluorescein-concanavalin A conjugate before bud initiation (Fig. I $a$ ), the bud which subsequently formed was unlabelled (Fig. I $c$ and $\mathrm{I} e$; corresponding dark-field photomicrographs are presented for comparison in this and other Figures). In addition, the intensity of the fluorescence exhibited by the mother cell did not decrease detectably during bud initiation and growth (Fig. I $a, c, e$ ). Thus, it appears that, at least in the early stages of cell division, very little new mannan is laid down at the surface of the mother cell and that the major portion of the mannan which is deposited about the growing bud is not derived from the wall of the parental yeast but is newly synthesized.

In yeasts stained late in the budding cycle (Fig. $2 a$ ), subsequent development resulted in the appearance of a non-fluorescent band between the mother and daughter cells (Fig. 2c) suggesting that the wall material which is inserted into the bud and birth scars is also newly 

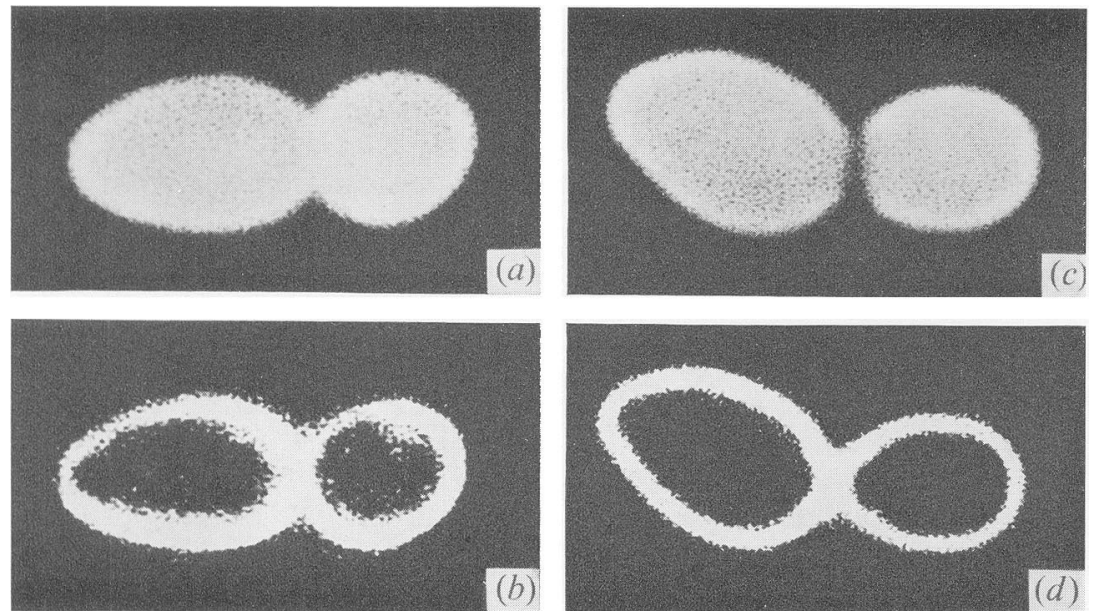

Fig. 2. Reconstructed sequence showing the development of a yeast exposed to fluoresceinlabelled concanavalin A late in the division cycle. A non-fluorescent band appears between the mother and daughter cells. $a, c$ : Fields under ultraviolet illumination; $b, d$ : corresponding dark-field photomicrographs.
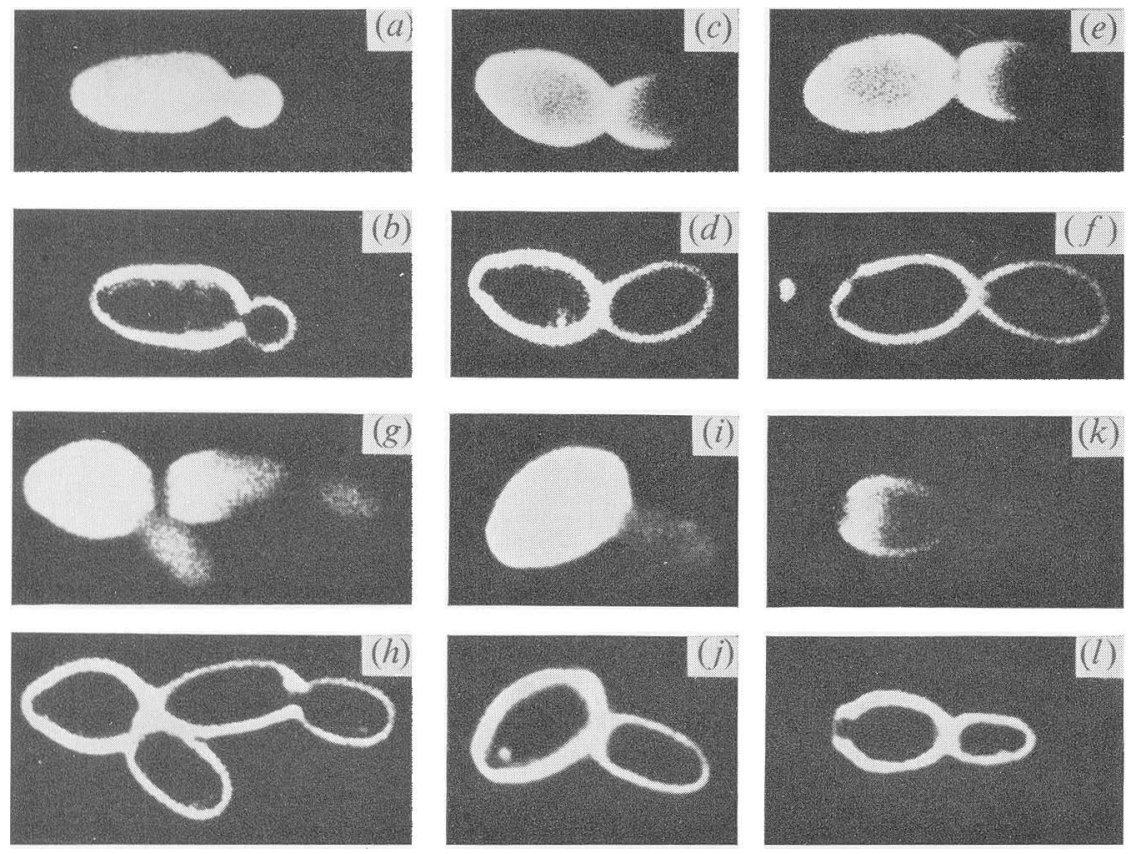

Fig. 3. Reconstructed sequence showing the appearance of newly-synthesized mannan in the wall of a yeast stained mid-way in the budding cycle. New mannan is inserted at the tip of the firstgeneration bud and entirely surrounds the second-generation buds. $a, c, e, g, i, k$ : Fields under ultraviolet illumination; $b, d, f, h, j, l$ : corresponding dark-field photomicrographs.

synthesized. That these scar regions did, in fact, contain concanavalin A-reactive material is indicated by the observation that on exposing a population of randomly dividing yeasts to fluorescein-labelled concanavalin A, each cell initially exhibited uniform fluorescence over its entire surface; the staining reagent did not distinguish between scars and surrounding wall 
material. Bud initiation by either of the two yeasts in Fig. $2(c)$ presumably proceeded as shown in Fig. I.

The sequence for a yeast which was stained mid-way in the budding cycle is presented in Fig. 3. With growth, deposition of new mannan was observed at the tip of the developing bud (Fig. 3 c). Again the formation of an unlabelled band between the mother and daughter cells was seen (Fig. $3 e, g$ ). The buds which appeared with the initiation of a new budding cycle were unlabelled (Fig. $3 g$ ). Cleavage of the two mature yeasts shown in Fig. 3( $g$ ) resulted in the liberation of the fully stained original mother cell with its new non-fluorescent bud (Fig. $3 i$ ) and of a cell which bore fluorescence in an annular band proximal to its unlabelled birth scar (Fig. $3 k$ ). The fluorescence of the latter yeast was acquired when it was a bud such as the one shown in Fig. 3(a). In the reconstructed sequence presented in Fig. 3, the buds have the same spatial relationship to the mother cell as that previously observed by Freifelder (1960) in his time-lapse photomicrographic examination of the budding process in diploid Saccharomyces cerevisiae cells.

\section{DISCUSSION}

Using fluorescein-labelled antibody generated against whole Saccharomyces cerevisiae cells, Chung, Hawirko \& Isaac (1965) established that wall replication in this yeast does not occur by an intercalation process over the entire surface. Rather, new wall material is deposited primarily about the growing bud. In addition, their study indicated that little, if any, of the material in the wall of the daughter yeast is derived from the surface of the mother cell. According to Mitchison (1958), the increase in cell volume which takes place during a division cycle is due to an increase in the volume of the bud; the volume (and thus the surface area) of the mother cell remains constant throughout the cycle. However, Mortimer \& Johnston (1959) found that the surface area of a given mother cell increases with repeated budding cycles in a manner proportional to the number of bud scars. This has been taken as an indication that bud scars do not replace portions of the original wall but fill regions opened during bud formation. Chung et al. (1965) demonstrated that the material which comprises the bud and birth scars is not derived from the wall of the mother yeast but is synthesized de novo, probably during the final stages of the budding cycle. This conclusion has been supported by recent cytological studies in the electron microscope (Marchant \& Smith, 1968; Sentandreu \& Northcote, I969). Clearly, the results which were obtained with fluorescein-concanavalin A conjugate are completely consistent with the foregoing views of wall replication in $S$. cerevisiae. As shown in Fig. I, most new mannan was deposited in the wall which surrounded the forming bud. Little if any wall mannan at the surface of the daughter cell was derived from the wall of the parental yeast. Deposition of new mannan in the mother cell was not detected except for that which occurred in the bud scar (Fig. 2, 3).

The present experiments further revealed that the distal tip of the growing bud was the major site at which new mannan was inserted into the existing wall fabric (Fig. 3). The same area has previously been identified by Johnson \& Gibson (1966) as the chief deposition site for newly synthesized glucan. This conclusion was reached by an autoradiographic investigation of the incorporation of tritiated-glucose into the alkali-insoluble component of the wall. The observation that 2-deoxy-glucose causes lysis of a dividing Saccharomyces cerevisiae cell at the apex of the bud constitutes indirect supporting evidence that this area is involved in wall replication (Johnson, I968). In contrast, Chung and co-workers (I965) reported that an annular band at the base of the forming bud is the area of active wall replication. Unfortunately, they did not provide information concerning the nature of the antigenic determinants (protein or polysaccharide) which were recognized by the anti- 
bodies employed in their studies, and it is difficult, therefore, to reconcile their findings with those of Johnson \& Gibson (I966) and those presented here. It would appear that Chung et al. (1965) observed the deposition of wall components other than glucan and mannan, and that, at least with regard to these two major wall polysaccharides, wall replication in Saccharomyces cells proceeds in a manner analogous to the apical mode known to occur in filamentous fungi.

This investigation was supported by Public Health Service grant AI-04572 from the National Institute of Allergy and Infectious Diseases. J. Tkacz was a predoctoral trainee under Public Health Service training grant GM-507 from the National Institute of General Medical Sciences. We thank Dr Neil Orenstein for his advice and assistance with the photographic problems encountered during this study. This paper was presented at the 7Ist Annual Meeting of the American Society for Microbiology, Minneapolis, Minnesota, U.S.A. on 2 to 7 May 197 I.

\section{REFERENCES}

Chung, K., Hawirko, R. \& IsaAc, P. (1965). Cell wall replication in Saccharomyces cerevisiae. Canadian Journal of Microbiology II, 953-957.

Cole, R. (1965). Bacterial cell-wall replication followed by immunofluorescence. Bacteriological Reviews 29, 326-344.

FREIFELDER, D. (1960). Bud position in Saccharomyces cerevisiae. Journal of Bacteriology 80, 567-568.

JoHnson, B. (1968). Lysis of yeast cell walls induced by 2-deoxyglucose at their sites of glucan synthesis. Journal of Bacteriology 95, I169-1172.

Johnson, B. \& Gibson, E. (1966). Autoradiographic analysis of regional cell wall growth of yeasts. III. Saccharomyces cerevisiae. Experimental Cell Research 4I, 580-59I.

MarChant, R. \& SMITH, D. (I968). Bud formation in Saccharomyces cerevisiae and a comparison with the mechanism of cell division in other yeasts. Journal of General Microbiology 53, I63-169.

Mitchison, J. (1958). The growth of single cells: II. Saccharomyces cerevisiae. Experimental Cell Research $\mathbf{1 5}$, 2I4-22 I .

Mortimer, R. \& Johnston, J. (1959). Life span of individual yeast cells. Nature, London 183,1751-1752.

Sentandreu, R. \& NorthCote, D. (1969). The formation of buds in yeast. Journal of General Microbiology 55, 393-398.

TKaCZ, J., Cybulska, E. \& Lampen, J. O. (1971). Specific staining of wall mannan in yeast cells with fluorescein-conjugated concanavalin A. Journal of Bacteriology 105, I-5.

WINGE, O. \& ROBERTS, C. (I 957). A genetic analysis of melibiose and raffinose fermentation. Comptes rendus des travaux du Laboratoire Carlsberg 25, 419-459. 